\title{
Slow Active Suspension Control for Rollover Prevention
}

\author{
Sarel F. van der Westhuizen ${ }^{1 \& 2}$ and Pieter S. Els ${ }^{1 \& 3}$ \\ ${ }^{1}$ University of Pretoria, Corner of Lynnwood Road and Roper Street, Pretoria, South Africa \\ Department of Mechanical and Aeronautical Engineering, University of Pretoria, Private Bag X20, \\ Hatfield, 0028 \\ ${ }^{2}$ francoisvdw@up.ac.za \\ schalk.els@up.ac.za (Corresponding Author)
}

\begin{abstract}
Rollover prevention in of off-road vehicles presents a significant challenge for vehicle safety. This paper postulates that by reducing the body roll angle of the vehicle, the load transfer will increase and thus the lateral forces generated by the tires will be decreased. This decrease in the lateral force can cause the vehicle to slide rather than to roll over. This paper presents the possibility of using slow active suspension control to reduce the body roll and thus reduce the rollover propensity. Using a validated Adams model to simulate a double lane change manoeuvre, performed by a SUV at 60 $\mathrm{km} / \mathrm{h}$, it is shown that a significant improvement in body roll can be obtained with relatively low energy requirements. Simulation results are confirmed with experimental results.
\end{abstract}

Keywords: Suspension control, Hydropneumatic suspension, Roll stability, Sports Utility Vehicle, Rollover prevention, slow active

\section{Introduction}

Although many Sports Utility Vehicles (SUV's) are designed as off-road vehicles these vehicles spend large amounts of time traveling on roads at high speeds and on-road dynamics becomes more important as the popularity of these vehicles increase. Off road vehicles require large suspension travel and good ground clearance to enable the vehicle to drive over large obstacles while maintaining contact between the wheels and the ground. This results in a vehicle with a high centre of gravity (CG) and a soft suspension that allows large angles of body roll which in turn result in a vehicle prone to rollover. According to [1] the particular on-road usage of SUV's makes these vehicles more prone to accidents.

According to the Georgia Governor's Office of Consumer Affairs [2] more than 40\% of drivers think that they are safer in a SUV than in a compact car and nearly 50\% do not take into account that loading increases the risk of rollover. This is shocking in the light that $37 \%$ of fatal crashes in SUV's were due to rollovers while only $15 \%$ of fatal accidents in passenger cars were due to rollover. In 2006 SUVs also had the highest occupant fatality rate in rollover crashes namely 7.77 per 100,000 registered vehicles and single-vehicle rollover crashes made up $47 \%$ of driver deaths in SUVs. In $2006,65 \%$ of single vehicle crashes involved SUVs.

The rollover statistics for Pennsylvania show similar trends [3]. In 2008, 8.5\% of light truck, van and SUV accidents were due to rollover where $5 \%$ of passenger cars rolled over. Of these rollover cases the occupant death was nearly $70 \%$ higher in SUV's than in passenger cars.

In South Africa rollover accidents made up 24\% of the fatal crashes and 25\% of the fatalities for 2009 [4]. This again shows the severity of a rollover accident.

According to [1] these vehicles are also popular amongst younger people that often drive more recklessly. The dynamics of these vehicles are generally worse than those of smaller sized passenger cars. The large side area of the vehicle combined with general softer suspension makes it vulnerable to side winds while the high Centre of Gravity (CG) magnifies the rolling motions during cornering. 
The high viewpoint of the driver also inspires confidence, because the driver can see further, and the driver may become over confident.

These are just a few motivations for the very urgent need for better rollover stability or control in SUV's. From these statistics it becomes clear that rollover is a very dangerous type of accident with a high fatality rate. This is likely because there is very little occupant protection in vehicles in the case of a rollover accident.

This paper is concerned with the on-road handling and rollover behaviour of vehicles that are primarily designed and used off-road. The on- and of-road performance of these vehicles is in conflict and it is almost impossible to address these conflicting design issues by passive means. Although the simulation and experimental validation performed in this study is based on on-road conditions, the same properties apply to off-road conditions. Under off-road conditions the proposed active roll control system can have added advantages e.g. levelling the vehicle body when driving on side slopes.

\section{$1.1 \quad$ Rollover}

When cornering at high speeds lateral acceleration is generated which causes a centrifugal force to act on the $\mathrm{CG}\left(\mathrm{F}_{\mathrm{y}}\right.$ in Fig. 1). The roll centre of the vehicle is the point where the lateral forces are transferred from the axle to the body of the vehicle. The lateral load transfer on the inside and the outside wheels can be determined using the following equation:

$F_{z o}-F_{z i}=2 F_{y} \frac{h_{r}}{t}+2 K_{\varnothing} \frac{\emptyset}{t}$

Where:

$F_{z o}=$ Vertical load on the outside wheel

$F_{z i}=$ Vertical load on the inside wheel

$F_{y}=F_{y i}+F_{y o}=$ Lateral Force

$h_{r}=$ Roll centre height

$t=$ Track width

$K_{\varnothing}=$ Roll stiffness of the suspension

$\varnothing=$ Roll angle of the body

The first part of the equation $2 F_{y} \frac{h_{r}}{t}$ is the transfer of the lateral load due to the cornering forces and can only be improved by widening the track of the vehicle or by lowering the CG which is not within the scope of this study.

The second part $2 K_{\varnothing} \frac{\emptyset}{t}$ is a transfer of the lateral load due to body roll. It can be seen from (1) that if the roll angle is reduced the load transfer will be smaller and the vehicle's tendency to roll over will be less due to a smaller $F_{y o}$ at point A in Fig. 1. However to reduce the roll angle the roll stiffness needs to increase which increases the load transfer. Due to the non-linearity between the vertical tyre load and the lateral tyre force, the lateral force that the tyres can generate is reduced when load is transferred. If the lateral force is reduced enough the vehicle will slide rather than roll over [5].

SUV's have undesirable geometry in terms of handling dynamics mostly due to their high centres of gravity. Unogren et.al. [6] evaluates the effect of a Vehicle Stability Control (VSC) system on the rollover propensity of a SUV using CarSim [7] and TruckSim [8]. According to the National Highway Traffic Safety Administration (NHTSA) of the United States of America the Static Stability Factor (SSF) is the most reliable measure of the vehicle's tendency towards untripped rollover. The author uses an evaluation method where, in the models, the disturbances are modelled as a worst case. The control input is however optimised for the disturbance inputs. The author comes to the conclusion that the vehicle's tendency to roll over can be improved by a VSC system. This shows that the dynamics of a vehicle with undesirable geometry like an SUV can be improved by other means than to change the geometry. 


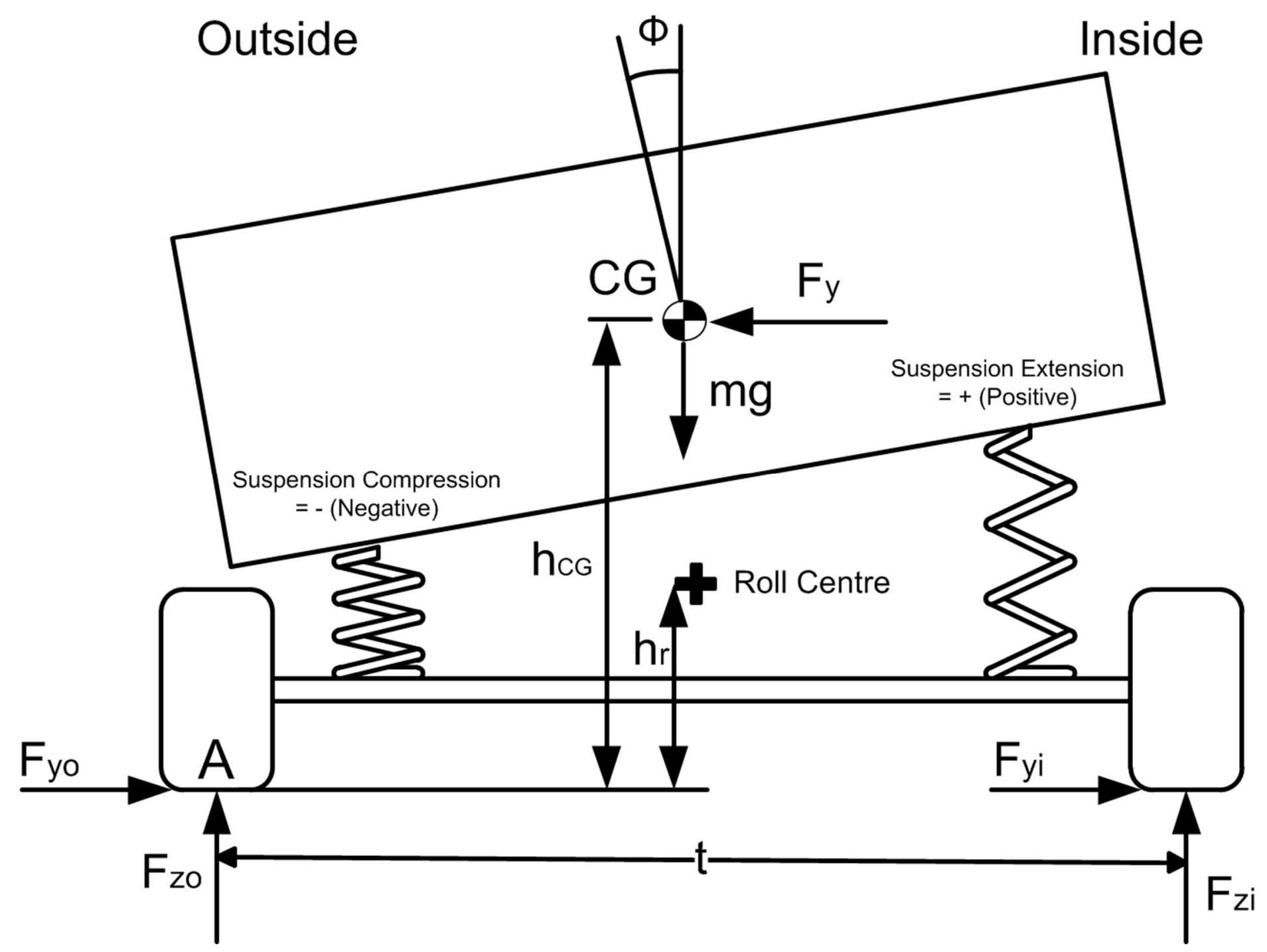

Fig. 1 Force analysis of a vehicle during cornering 


\subsection{Handling}

The quality of the handling of a vehicle is determined by the ease with which a human can control the vehicle, in other words a vehicle that is easy to control has good handling and a vehicle that is difficult to control has poor handling. There is currently no universal method that can quantify the controllability of a vehicle seeing that various human beings will experience the controllability of a vehicle in different ways.

To test the dynamic handling of a vehicle a severe Double Lane Change (DLC) manoeuvre can be used. The DLC manoeuvre is defined by the International Organisation for Standardisation [9]. The DLC manoeuvre can be used to test the dynamic handling of a vehicle and gives an indication of the road holding ability of a vehicle. In this paper this manoeuvre will be used in a comparative test where the performance of the suspension control will be evaluated against the vehicle's baseline.

\subsection{Four State Semi-Active Suspension}

The $4 \mathrm{~S}_{4}$ (4 State Semi-active Suspension System) is a suspension developed by Els [10] which uses semi-active hydropneumatic springs and hydraulic dampers. The $4 \mathrm{~S}_{4}$ was optimised to give optimal ride comfort (soft springs and low damping) and to give optimal handling (hard springs and high damping) on its specific settings. The ride comfort was optimised by minimising the vertical acceleration and the handling by minimising the body roll angle when performing a DLC. The $4 \mathrm{~S}_{4}$ can switch between hard and soft spring settings and between high and low damping in less than 100 milliseconds. Switching between the different settings happens automatically based on acceleration measured on the vehicle body. The switching is done by opening or closing solenoid valves. A schematic diagram of a $4 \mathrm{~S}_{4}$ unit can be seen in Fig. 2. The wheel displacement relative to the vehicle body results in a displacement of the piston in the main strut which is filled with oil, the oil then in turn is pushed through the damper packs or valves until the oil pressure and the pressure of the accumulator equalises. If valve 3 is closed the suspension is on the stiff spring setting where only the 0.1 litre nitrogen accumulator is used as a pneumatic spring. If valve 3 is open it is on the soft spring setting where both the 0.4 litre and the 0.1 litre accumulators serve as a pneumatic spring. If valves 1 and 2 are closed the system has high damping because the oil is forced to flow through the damper pack, and if they are open the system has low damping because the oil can flow past the damper pack through the open valve. This suspension has been implemented successfully on a Land Rover Defender 110 at the University of Pretoria.

\section{Simulation Results}

The aim of this study is to improve the rollover stability of the vehicle by increasing the load transfer during cornering. This is achieved by reducing the body roll of the vehicle. The most common method in use today is anti-roll bars in active, semi-active or passive configurations. This study will however determine the feasibility of controlling the body roll by means of controlling each suspension unit separately. This is done by adding or removing oil from the $4 \mathrm{~S}_{4}$ suspension units fitted on the University of Pretoria's Land Rover test vehicle. This approach differs from active anti-roll bars because energy can only be supplied when lifting the suspension and not when lowering, effectively making it a single acting hydraulic actuator requiring highly non-linear control. The model that will be used in this study is a validated Adams [11] model of a Land Rover Defender 110 with a Simulink [12] interface developed by Thoresson [13]. Throughout this study extension of the suspension will be seen as positive and compression as negative.

\subsection{Ideal Gas Model}

Initial simulations were performed using the original ideal gas law suspension models, in the model developed by Thoresson [13]. These results showed that a significant improvement in body roll is achievable. Some concerns regarding the accuracy of the ideal gas law in this application arose. The concerns were that calculation errors could be introduced due to the fact that, the ideal gas law does not take the intermolecular forces at small intermolecular distances into account. It therefore over 


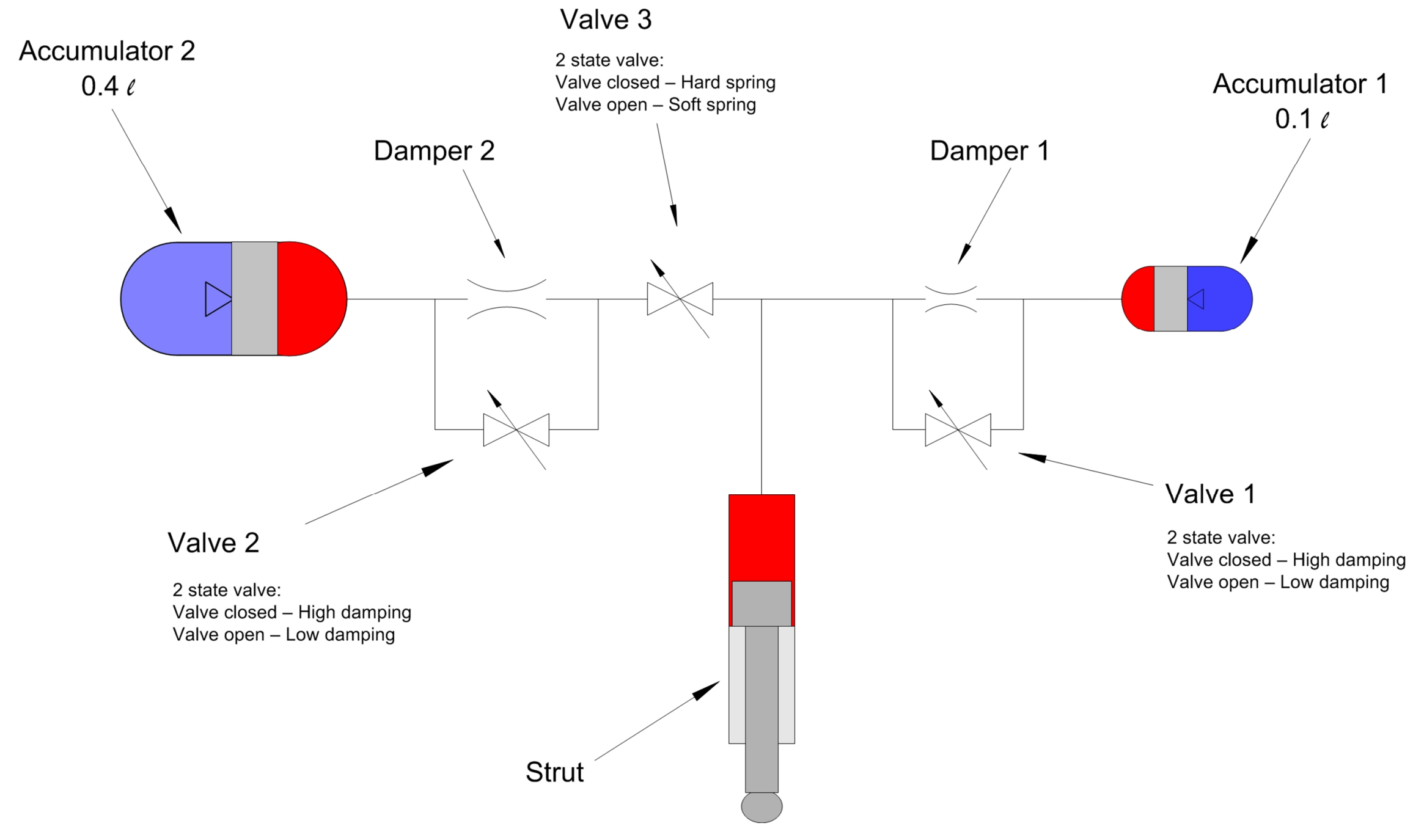

Fig. 2 Schematic diagram of the 4S4 
estimates the compressibility at either high pressures or low temperatures, of which the former is present when working with hydropneumatic suspensions [14]. In the initial verification test the ideal gas model correlated well with the measured results, but this is done at low pressures while the vehicle is standing still (see measured and ideal gas results in Fig. 3). Subsequently the Benedict Webb Rubin (BWR) real gas equation was introduced [15]. However, during the simulation of the DLC the flow requirements for the ideal gas model are much higher than that of the BWR model. This is likely due to the above mentioned problems and the BWR model is expected to deliver more accurate results.

\subsection{Benedict Webb Rubin Model}

In order to improve the results a real gas approach such as the BWR eq. (2) is used to calculate the suspension force [15].

$P=\frac{R T_{g}}{v}+\frac{B_{o} R T_{g}-A_{o}-\frac{C_{o}}{T_{g}^{2}}}{v^{2}}+\frac{b R T_{g}-a}{v^{3}}+\frac{a \alpha}{v^{6}}+\frac{c\left(1+\frac{\gamma}{v^{2}}\right) e^{\frac{-\gamma}{v^{2}}}}{v^{3} T_{g}^{2}}$

The BWR model correlates well with the measured values as can be seen in Fig. 4. This model, as well as the ideal gas model does however deviate quite substantially from the measurements if the displacement goes into the negative. This is due to the manner in which the damping is modelled. The damping causes the suspension to lower at a slower rate than at which the oil is removed. This causes the gas to expand more than in reality which then predicts a smaller suspension force. The net effect is that the suspension lowers more and faster than in reality. The results can be seen in Fig. 3 where the simulation results overshoot the measured results when the suspension is lowered.

This model is used to simulate a DLC manoeuvre at $60 \mathrm{~km} / \mathrm{h}$. The suspension displacement is controlled by adding or removing oil from each suspension unit. Oil is supplied from an accumulator at $12.5 \mathrm{MPa}$ which is also modelled using the BWR equation. A Proportional-Integral-Derivative (PID) controller is used to choose between pumping oil in, draining oil or to close the valve. The model selects between high or low flow using the lateral acceleration as input. Initial simulations showed that draining too much oil from a suspension unit in order to keep the displacement zero has a negative effect on the handling. Therefore oil is only drained until a little less than the original amount of oil is left in the suspension. It should be noted again that energy can only be supplied when adding oil, but draining oil is subject to the pressure in the system. The flow requirements are relatively low and an average flow for all suspension units of $4.51 / \mathrm{m}$ was obtained using the BWR simulations, this result in an average power consumption of below $1.5 \mathrm{~kW}$. Simulations show that a substantial improvement is possible on the body roll angle of the vehicle (See Fig. 5).

\section{Experimental results}

Initially the PID controller output values were filtered with a 5 point running average filter. However, the derivative term gave erroneous values due to the noise present in the displacement signals. Therefore the displacement signals were filtered with a 5 point running average filter and the PID values were then calculated from the filtered displacement signals. This was found to improve the results quite substantially.

Hydraulic power was supplied by a 10 litre accumulator, which can store about 3 litre of oil at $12.5 \mathrm{MPa}$. The accumulator was charged before each test run using a $12 \mathrm{~V}$ battery powered hydraulic pump. This solution however limits the duration that the suspension can be controlled and it also limits the maximum oil flow. An estimated average oil flow of about $3.5 \mathrm{l} / \mathrm{min}$ was obtained during the tests which results in an average power consumption of under $1 \mathrm{~kW}$.

One of the proportional valves were characterised to determine the flow rate across the valve as a function of the input voltage. It was assumed that all valves will share the same characteristics. However it was later found that all the valves do not respond exactly the same, and some adjustments had to be made in the field. In Fig. 6 it can be seen that the flow of the left suspension units was too low, but there is a significant improvement in the displacement of the right suspension units where the 

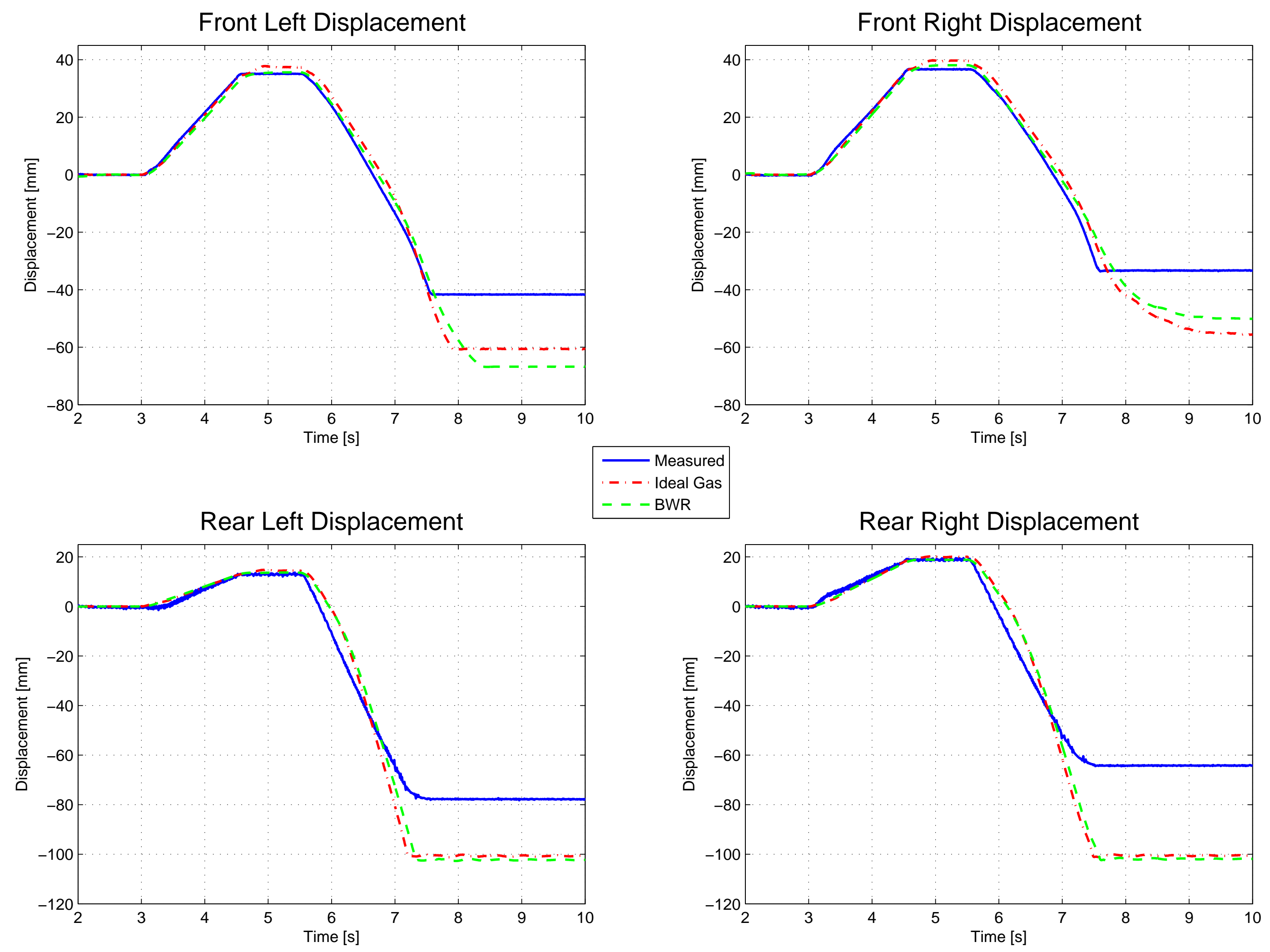

Fig. 3 Measured and simulated results for raising and lowering 


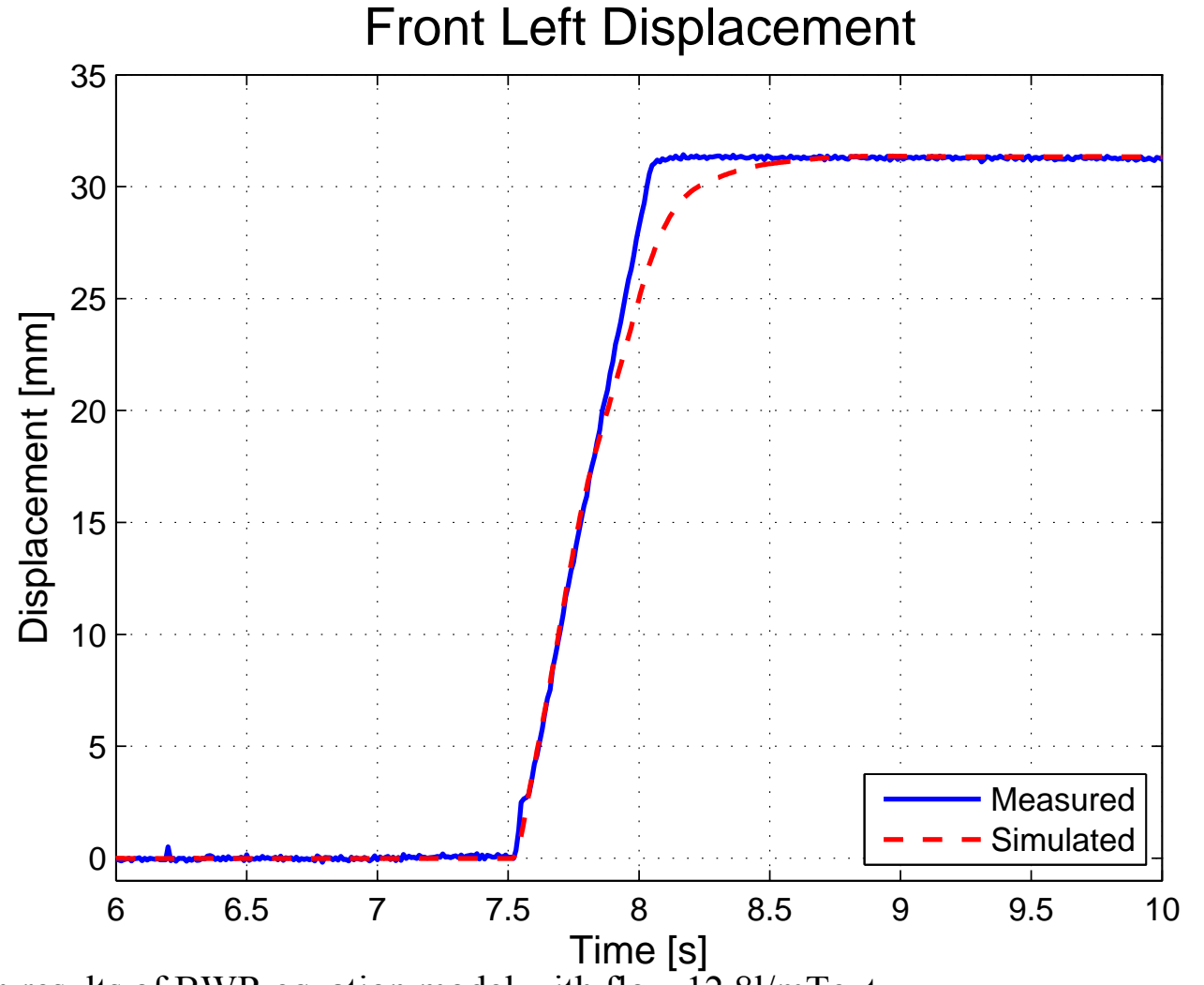




$$
\text { Roll Angle }
$$

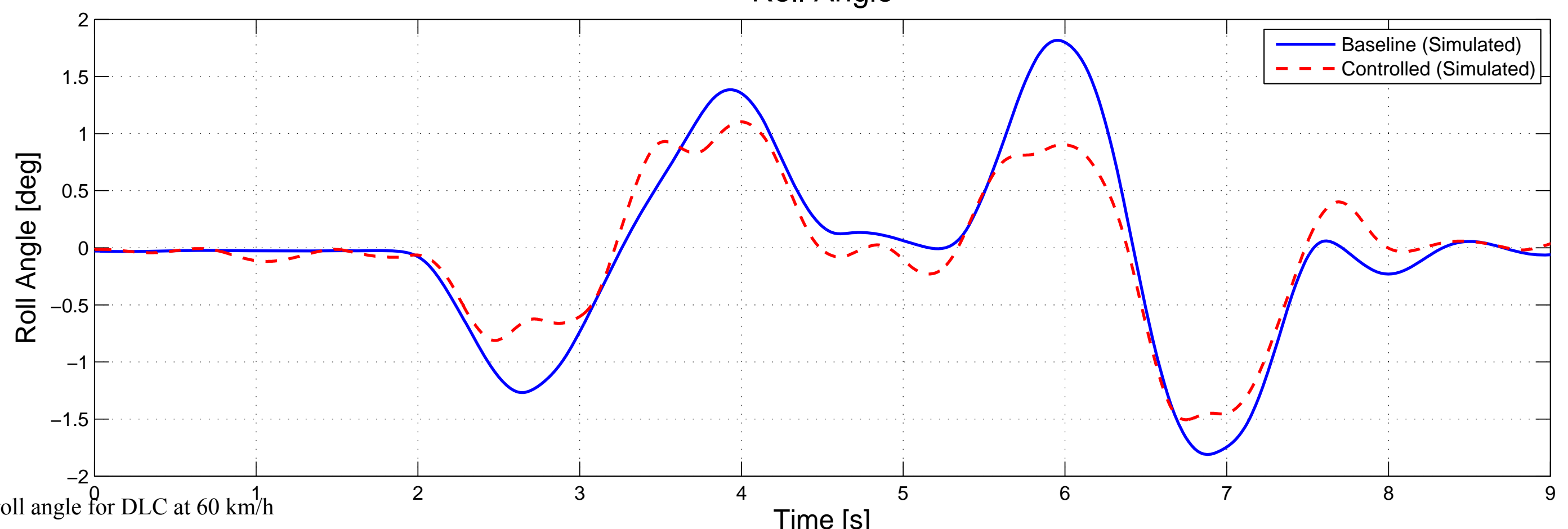

Fig. 5 Bodyroll angle for DLC at $60 \mathrm{~km} / \mathrm{h}$ 
flow was somewhat higher. Results could be further improved if characteristics for each individual valve were used.

In order to estimate the amount of oil in the suspension unit, the equation for the bulk modulus of fluid is used in combination with the ideal gas equation. The volume of the nitrogen is estimated using the ideal gas law while the compression of the oil is calculated using the bulk modulus equation. The amount of oil in the suspension units are estimated to prevent the control algorithm from draining too much oil from the suspension, as this will result in a negative effect on the suspension response. Although the signals are filtered there is still a substantial amount of noise present, because filtering out lower frequencies will cause an excessively large delay. Due to the change in volume of oil in the suspension being relatively small, the noise on the measured signals has a severe effect on the accuracy of the volume estimation. Friction also affects the estimated volume of oil to some extend but the effect is relatively small. After testing it was found that the limits for the minimum volume of oil in the suspensions were set too low. It is visible that the effect is more unfavourable on the left suspension units where the oil flow was lower and where there was a longer continuous time for the oil to flow out, due to the suspension being extended between 5-9s as can be seen in Fig. 6 .

In Fig. 7 an improvement in the body roll angle can be seen even though the system was not set up optimally. Fig. 8 shows the vehicles path and speed during the two runs and the consistency between the two runs is very good. Fig. 9 compares the measured and simulated roll angles with similar setups.

\section{Conclusions and Recommendations}

The results show that a significant improvement in body roll angle is possible by actively controlling the amount of oil in each of the hydropneumatic suspension struts. This also provides the possibility to cancel out squat and pitch. This setup further enables height adjustment on the vehicle. The flow requirements are relatively low and an average flow for all suspension units of $4.5 \mathrm{l} / \mathrm{m}$ was obtained using the BWR simulations. The average flow for the experimental tests is estimated to be around 3.5 $1 / \mathrm{m}$. The suspension displacements on the right were improved in all aspects and similar results should be possible for all the suspension units. A more accurate method of determining the volume of oil in the suspension is also expected to improve the results. Better improvement might also be possible on a softer suspension where there are larger displacements but due to oil flow limitations this was not tested. Using suspension control will enable one to use, with some minor changes, the height control on vehicles to replace the anti-roll bar. Individual suspension control will also give the possibility of changing the handling characteristics while driving to suit the specific situation best. Thus, this method of roll control is feasible with added advantages over that of an active anti-roll bar.

This study was only concerned with on-road dynamics. The simulation and testing should be expanded in the future to include off-road conditions as well transient conditions such as a vehicle leaving the road and some of the wheels are on the road while others are on off-road terrain. The challenge here is to find a suitable terrain where these tests can be performed safely. These tests will have to be done at lower speeds and a suitable manoeuvre to quantify off-road handling will have to be investigated. 

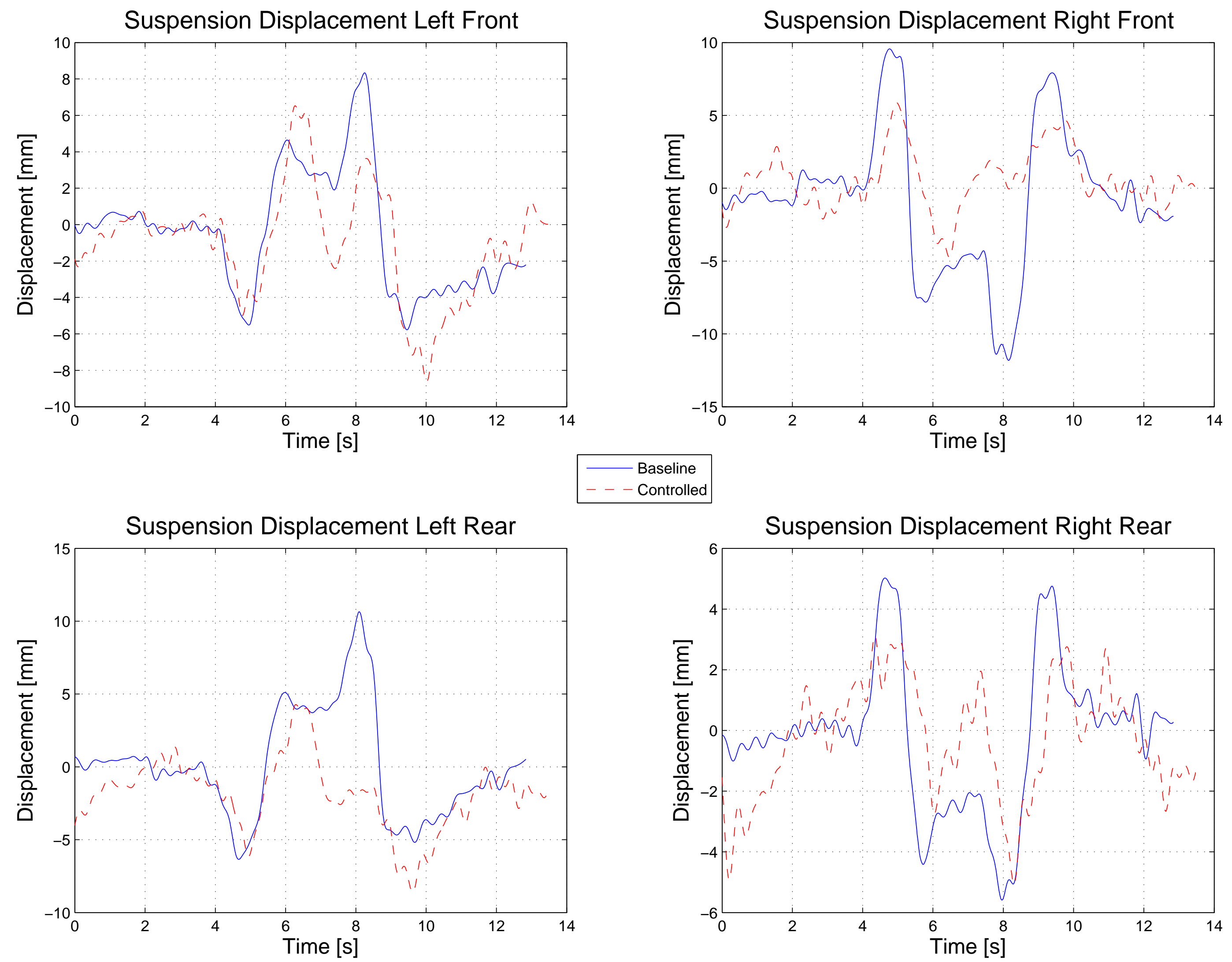

Baseline

Controlled

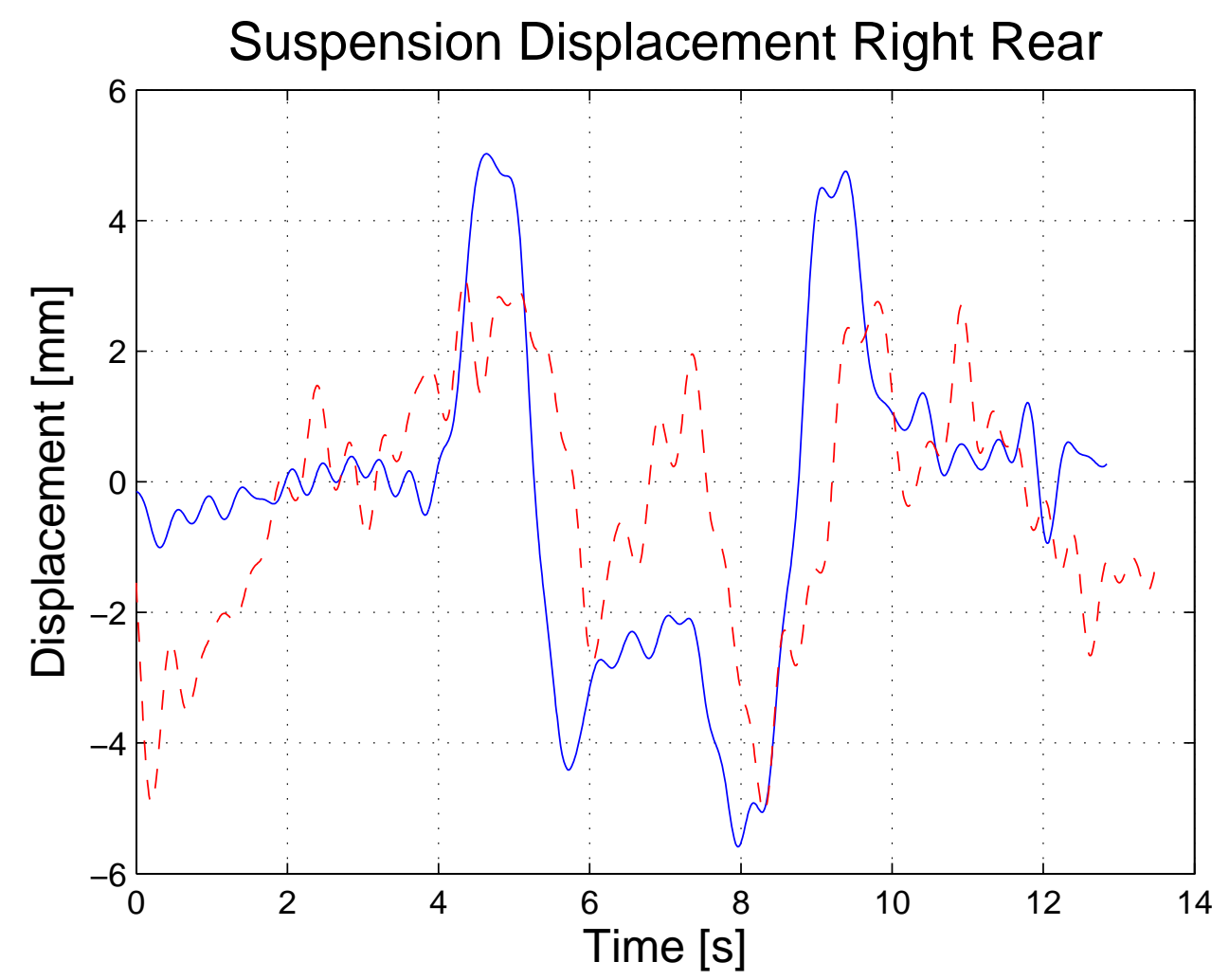




\section{Nomenclature}

$\begin{array}{lll}F_{y} & \text { Lateral Force } & {[\mathrm{N}]} \\ F_{y o} & \text { Lateral load on the outside wheel } & {[\mathrm{N}]} \\ F_{y i} & \text { Lateral load on the inside wheel } & {[\mathrm{N}]} \\ F_{z o} & \text { Vertical load on the outside wheel } & {[\mathrm{N}]} \\ F_{z i} & \text { Vertical load on the inside wheel } & {[\mathrm{N}]} \\ h_{r} & \text { Roll centre height } & {[\mathrm{m}]} \\ t & \text { Track width } & {[\mathrm{m}]} \\ K_{\varnothing} & \text { Roll stiffness of the suspension } & {[\mathrm{Nm} / \mathrm{rad}]} \\ \varnothing & \text { Roll angle of the body } & {[\mathrm{rad}]} \\ P & \text { Pressure } & {[\mathrm{Pa}]} \\ R & \text { Gas Constant } & {[\mathrm{kJ} / \mathrm{kgK}]} \\ T_{g} & \text { Gas Temperature } & {[\mathrm{K}]} \\ v & \text { Specific Volume } & {\left[\mathrm{m}{ }^{3} / \mathrm{kg}\right]} \\ B_{o} & \text { BWR Gas Constant } & \\ A_{o} & \text { BWR Gas Constant } & \\ C_{o} & \text { BWR Gas Constant } \\ a & \text { BWR Gas Constant } \\ \alpha & \text { BWR Gas Constant } & \\ C & \text { BWR Gas Constant } & \\ \gamma & \text { BWR Gas Constant } & \\ C G & \text { Centre of Gravity } & \\ & & \end{array}$




\section{References}

[1] Takubo, N. and Mizuno, K., 2000, Accident analysis of sports utility vehicles: human factors from statistical analysis and case studies, JSAE Review, Vol.21, 2000.

[2] Governor's Office of Consumer Affairs, 2010, SUV Rollover Accident and Death Statistics, http://www.georgia.gov/gta/mcm/content/article print_front/0,2089,5426814 390390813882061 2,00.html, Accessed 28 July 2010.

[3] Edgar Snyder and Associates, 2010, Rollover Car Accident Statistics, http://www.edgarsnyder.com/car-accident/rollover-accidents/statistics.html, Accessed 1 November 2010.

[4] Road Traffic Management Corporation, 2009, Road Traffic Report for the Calendar Year 2009, http://www.arrivealive.co.za/ documents/Year_2009___Road_Traffic_Report_-_V2.pdf, Accessed: 24 January 2011.

[5] Gillespie, T. D., 1992, Fundamentals of vehicle dynamics, Society of Automotive Engineers Inc., Warrendale, 1992.

[6] Ungoren, A.Y., Peng, H. and Milot, D.R., 2001, Rollover Propensity Evaluation of an SUV Equipped with a TRW VSC System, University of Michigan, January 2001.

[7] Mechanical Simulation, 2011, CarSim, http://www.carsim.com/products/carsim/index.php, Accessed: 31 May2011.

[8] Mechanical Simulation, 2011, TruckSim, http://www.carsim.com/products/trucksim/, Accessed: 31 May2011.

[9] International Organisation for Standardisation, 1999, International Organisation for Standardisation ISO 3888-1: Passenger vehicles - test track for a severe lane - change manoeuvre, ISO 3888-1:1999(E).

[10] Els, P. S., 2006, The ride comfort vs. handling compromise for off-road vehicles, Unpublished $\mathrm{PhD}$ thesis, University of Pretoria, Pretoria, http://upetd.up.ac.za/thesis/available/etd-07152008102911/, Accessed: 7 June 2011.

[11] MSC.Software, 2011, ADAMS Multibody Dynamics, http://www.mscsoftware.com/Products/CAE-Tools/Adams.aspx, Accessed: 30 May 2011.

[12] MathWorks, 2011, Simulink - Simulation and Model-Based Design, http://www.mathworks.com/products/simulink/, Accessed: 31 May2011.

[13] Thoresson, M. J., 2003, Mathematical optimisation of the suspension system of an off-road vehicle for ride comfort and handling, Unpublished M.Eng thesis, University of Pretoria, Pretoria, http://upetd.up.ac.za/thesis/available/etd-11162005-155118/, Accessed: 7 June 2011.

[14] Sontag, R. E. and Van Wylen, G. J., 1991, Introduction to thermodynamics, $3^{\text {rd }}$ ed., John Wiley and Sons, New York, 1991.

[15] Otis. D.R. and Pourmovahed, A., 1985, An Algorithm for Computing Nonflow Gas Processes in Gas Springs and Hydropneumatic Accumulators, Transactions of the ASME, Journal of Dynamic Systems, Measurement and Control, vol 107, March 1985, pp.110-118. 